\title{
Micotoxicose em gado leiteiro no município de Orizona, Goiás - relato de caso
}

Giovanna Vieira Rocha', Victor Thiago Pires Pinheiro, Marina Santos da Silva, Paulo José Bastos Queiroz, Ozana de Fátima Zacaroni, Milton Luiz Moreira Lima, Paulo Henrique Jorge da Cunha

Escola de Veterinária e Zootecnia, Universidade Federal de Goiás (UFG), Goiânia, GO, Brasil

*Autor correspondente

e-mail: giovannavieirar6@gmail.com

\section{Resumo}

As micotoxinas são sintetizadas por várias espécies de fungos e podem ocasionar intoxicações quando animais ingerem alimentos contaminados. Os principais fungos produtores de micotoxinas são Aspergillus, Fusarium e Penicillium. Os sintomas das micotoxicoses dependem da micotoxina envolvida e são geralmente inespecíficos. A confirmação do diagnóstico é complexa devido à presença de várias micotoxinas no alimento, distribuição não uniforme, interação com outros fatores ambientais, dificuldade na colheita de amostras e alto custo dos exames. 0 presente trabalho objetivou relatar aspectos clínicos e laboratoriais de uma intoxicação por micotoxinas em bovinos leiteiros no estado de Goiás. Segundo o proprietário, os principais sinais clínicos identificados foram apatia, queda brusca na produção de leite, inapetência, diarreia, decúbito e morte em menos de 48 horas. Na propriedade, morreram 18 vacas em lactação em um período de 3 meses. A dieta era composta por silagem de milho, silagem de grão úmido de milho, polpa cítrica, caroço de algodão e concentrado. Durante a visita da equipe técnica do HV/EVZ/UFG observou-se silagem com infiltração de água nas laterais, áreas com aumento de temperatura e alteração de coloração. 0 grão úmido também apresentava alteração de coloração. Diante disso, foram colhidas amostras de sangue de sete vacas que apresentavam sintomatologia clínica para avaliação hematológica e bioquímica sanguínea. Além disso, colheram-se amostras de todos os ingredientes da dieta, as quais foram encaminhadas ao Laboratório de Análises Micotoxicológicas (LAMIC-RS) para identificação de micotoxinas. As principais alterações hematológicas identificadas foram anemia (hematócrito $23 \pm 3,77 \%$ e hemoglobina 6,92 \pm 1,18 g/dL), leucocitose $(13.366,66 \pm 665,83 / \mu \mathrm{L})$ por neutrofilia $(6.636,7 \pm 1.386,3 / \mu \mathrm{L})$ e hiperfibrinogenemia $(1000$ $\pm 163,29 \mathrm{mg} / \mathrm{dL})$. Nas bioquímicas sanguíneas identificou-se elevação de GGT (27,8 \pm 4,81 UI/L), redução de bilirrubina direta $(0,012 \pm 0,004 \mathrm{mg} / \mathrm{dL})$, hipoalbuminemia $(2,82 \pm 0,12 \mathrm{~g} / \mathrm{dL})$ e hiperglobulinemia 
$(4,75 \pm 0,93 \mathrm{~g} / \mathrm{dL})$. Os resultados dos exames hematológicos e bioquímicos sanguíneos indicaram quadro de hepatopatia crônica. Identificou-se na silagem de grão úmido a presença de $491 \mu \mathrm{g} / \mathrm{kg}$ de fumosinas e $535 \mu \mathrm{g} / \mathrm{kg}$ de desoxinivalenol, e na silagem de milho encontrou-se $996 \mu \mathrm{g} / \mathrm{kg}$ desoxinivalenol. Diante desses resultados, confirmou-se a ocorrência de mortalidade ocasionada por micotoxicose e recomendouse a inclusão de adsorvente de micotoxinas na dieta (Aluminosilicato de Sódio e Cálcio, NotoxTM, Cargil Alimentos Ltda) na dose de $5 \mathrm{~kg} /$ ton de ração pronta e a retirada dos ingredientes contaminados da dieta. Após essas medidas, não foram observadas mais mortes no rebanho. Os resultados clínicos, hematológicos e bioquímicos indicaram quadro de hepatopatia crônica ocasionada pela ingestão de micotoxinas presentes na silagem e grão úmido, confirmada pelos exames laboratoriais. 